\title{
El gobierno irlandés ante la Guerra Civil Española Actividad legislativa y debates parlamentarios
}

\author{
GONZALO BUTRON PRIDA
}

\section{PRESENTACION}

La guerra civil española puede ser vista como una manifestación de las críticas circunstancias que afectaban a la sociedad europea de los años treinta. Estas condiciones eran, de alguna forma, una herencia de una situación desarrollada desde unas premisas parecidas a aquellas que habían provocado la Primera Guerra Mundial: la resistencia a aceptar ningún tipo de cambio, ni en la balanza internacional de poder ni en la estructura interna de cada país. A esto se unió la persistencia de un estado de crisis y la ascensión de nuevas ideologías de clara vocación combativa.

Estas circunstancias determinaron que la respuesta internacional a la guerra civil española se caracterizara por una falta de solidaridad; por una parte, las democracias occidentales no se comprometieron con la defensa de la joven democracia española; por otra, los países con regímenes autoritarios sólo llegaron a implicarse en España en busca de ventajas particulares.

Hasta cierto punto, Irlanda no participó de esta tendencia general. La solución de sus propios problemas internos la habían aislado de las circunstancias generales europeas, y su reacción ante la guerra civil española no estuvo tan condicionada por esas circunstancias como por su conciencia de la necesidad de resolver los problemas relacionados con la construcción de un estado irlandés. De este modo, Irlanda adoptó el no-intervencionismo como su política oficial, ya que ésta no sólo encajaba con el compromiso que su clase política había tomado con la neutralidad como signo de independencia, sino que también la respuesta irlandesa sintonizaba con la política del resto de las democracias occidentales. 
Estas eran dos buenas razones para justificar la política de No Intervención ante el país. Esta fórmula bloqueó cualquier reacción de la oposición, que sólo intentó atacarla mediante la denuncia de la continuidad de las relaciones diplomáticas entre Irlanda y el gobierno republicano de España.

\section{GLOSARIO DE TERMINOS IRLANDESES}

Cumann na nGaedheal (League of Gaels): partido político favorable al tratado Anglo-Irlandés de 1921.

Dáil Éireann cámara baja del parlamento irlandés.

Eire: nombre oficial de Irlanda recogido en la Constitución de 1937.

Fianna Fáil (Soldiers of Destiny): partido político fundado en 1926 por los detractores del Tratado Anglo-Irlandés de 1921.

Fine Gael (Tribe of Gaels): partido político sucesor del Cumann na nGaedheal en 1933.

Oireachtas: parlamento irlandés.

Saorstát Éireann (Irish Free State): nombre oficial de Irlanda entre 1922 y 1937.

Seanad: cámara alta irlandesa.

\section{LA POLITICA DEL GOBIERNO DEL FIANNA FAIL}

Al comenzar la guerra civil española, gobernaba en Irlanda el Fianna Fáil, partido que había llegado al poder en 1932 tras haber vencido al Cumann na nGaedheal en las elecciones generales. Era la primera vez que los perdedores de la guerra civil iban a formar gobierno, y se temía que los defensores del Tratado de 1921 precipitaran un golpe de estado para adelantarse a una posible venganza del Fianna Fáil desde el poder; sin embargo, esto no sucedió así, pues ambos bandos coincidieron en la comprensión de la necesidad de una transición sin violencia (1).

Una vez en el poder, el Fianna Fáil se marcó dos objetivos: redefinir las relaciones de Irlanda con el Imperio e instituir un estado de "proteccionismo" tanto económico como cultural (2).

En la persecución del primer objetivo, el gobierno de De Valera comenzó a desmantelar el Tratado y todo lo que éste implicaba; ini-

(1) LEE, J.J. Ireland. 1912-1985. Politics and Society. Cambridge, 1989. pp. 175-176.

(2) FOSTER, R. F. Modern Ireland. 1600-1972. London, 1988. p. 536. 
cialmente, este asalto tomó dos formas: la supresión del "Oath of Allegiance" de la constitución irlandesa y la suspensión de los pagos de las rentas vitalicias de la tierra al tesoro del Reino Unido (3). Con esta política, el Fianna Fáil empezaba la tarea de alcanzar las metas nacionalistas de 1916 por medios parlamentarios (4), tarea que sería finalmente completada, excepto en el tema de la partición, mediante la aprobación de la Executive Authoritative (External Association) Act de 1936 y la promulgación de la Constitución de 1937.

En el aspecto económico, De Valera deseaba hacer de Irlanda una república rural autosuficiente y genuinamente independiente (5). De todos modos, la formulación de su política económica no estuvo solo condicionada por este ideal, sino también por las consecuencias de la supresión del pago de las rentas vitalicias de la tierra, que motivó una dura respuesta británica: "the economic war" (6). Ambas circunstancias, ideológicas y políticas, llevaron a una política económica que consistió básicamente en el establecimiento de industrias nacionales y en la reorientación del uso de la tierra de lo ganadero a lo agrícola - "from catle to tillage" (7).

Por su parte, el proteccionismo cultural, en palabras del profesor Fannig, dio atención prioritaria a la defensa de los valores espirituales: la religión católica o "the faith of majority" (8) y la lengua irlandesa o "the first official language" (9).

Así, cuando empezó la guerra civil española, Irlanda se encontraba ocupada en la tarea de construir un nuevo Estado y de darle una identidad clara. En estas circunstancias, De Valera, después del colapso de la política de seguridad colectiva de la Sociedad de Naciones, se convenció de que lo mejor para Irlanda era conseguir una política de neutralidad como un medio de lograr sus aspiraciones de independencia, seguridad y unidad (10).

(3) LYONS, F. S. L. Ireland since the Famine. London, 1973. p. 511.

(4) BOWYER BELL, J. "Ireland and the Spanish Civil War" en Studia Hibernica. $\mathrm{n}^{\circ} 9$ (1969). p. 139.

(5) BROWN, TERENCE. Ireland. A social and Cultural History. 1922-1985. London, 1985. p. 142.

(6) FOSTER, R. F. op. cit. p. 539.

(7) Ibídem. pp. 540-541.

(8) FANNING, RONAN. Independent Ireland. Dublin, 1983. pp. 127-134.

(9) Ibídem. pp. 134-136.

(10) KEATINGE, PATRICK. A Place Among the Nations. Issues of Irish Foreign Policy. Dublin, 1978. p. 156. 
Para desarrollar esta política, el presidente contó con la ventaja de estar actuando dentro de una maquinaria política concentrada que le había permitido asumir también la cartera de Asuntos Exteriores; además, también contó con un partido disciplinado, cuya mayoría le permitía controlar el proceso parlamentario (11).

Frente a la guerra civil española, el gobierno del Saorstát Éireann, siguiendo esta pauta general de neutralidad, se decantó por la política de No Intervención y decidió unirse al recientemente establecido Comité de No Intervención. Con posterioridad, De Valera explicó que tal decisión se había tomado "in the belief that the policy of the NonIntervention Committee was the best in the interests of Spain itself as well as in the interests of European peace" (12).

En cumplimiento de los compromisos adquiridos, Irlanda prohibió hacia finales de 1936 la exportación de armas y municiones a España desde su territorio (13), para posteriormente afianzar su postura mediante la aprobación de dos leyes: la Spanish Civil War (NonIntervention) Act y la Merchant Shipping (Spanish Civil War) Act.

Aunque esta política no encontró, en sí misma, una oposición directa por cuanto existía cierto consenso general sobre la conveniencia de la neutralidad, en cambio sí se criticó el estado de las relaciones diplomáticas entre Irlanda y España y, desde los asientos de la oposición, se hicieron oir demandas en favor de la ruptura de las relaciones diplomáticas con el gobierno republicano y del reconocimiento del gobierno del general Franco.

\section{LA ACTIVIDAD LEGISLATIVA}

\section{A) La Spanish Civil War (Non-Intervention) Act}

La Spanish Civil War (Non-Intervention) Act fue la ley más importante aprobada en relación con la situación española. Eñ sentido estricto, esta ley prohibía a cualquier ciudadano unirse o hacerse miembro de las fuerzas militares de alguno de los bandos "beligerantes" y restringía la salida de ciudadanos hacia España y la venta de billetes con dicho destino; así mismo, daba poder al Executive Council para tomar medidas para prevenir la exportación de material de gue-

(11) Ibídem. p. 206.

(12) Dáil Debates. Volumen LXV. 18 de febrero de 1937. Columna 598 (D.D. LXV, $18 / 2 / 37,598)$.

(13) Ibídem. 
rra; por último, determinaba las penas a imponer por el incumplimiento de lo arriba estipulado (14).

El objetivo de la ley era el de dar efectividad al acuerdo alcanzado por el Comité de No Intervención el 17 de febrero de 1937, mediante el cual, el Acuerdo de No Intervención había sido ampliado "to cover the recruitment in, the transit through or departure from, their respectve countries of persons of non-Spanish nationality proposing to proceed to Spain or the Spanish dependencies or the purpose of taking service in the present civil war", para lo cual se había montado un sistema de supervisión de las fronteras terrestres y marítimas con España (15).

De acuerdo con las palabras del presidente, estas nuevas medidas fueron adoptadas para evitar que desde distintos países siguieran uniéndose voluntarios a alguno de los bandos españoles. Los gobiernos representados por el Comité de No Intervención pensaban que mientras que se siguieran vendiendo armas y municiones a España y siguieran dirigiéndose voluntarios allí, la guerra podría continuar indefinidamente. Para colmo, la presencia de voluntarios extranjeros incrementaba enormemente el peligro de un incidente internacional, lo que podía afectar seriamente a la paz de Europa (16).

Tras esta intervención inicial de De Valera, los diputados O’Sullivan y Belton presentaron sendas enmiendas a la ley, ambas relacionadas con el problema de las relaciones diplomáticas, pero mientras que la de O’Sullivan pedía la ruptura de las relaciones con el gobierno de Largo Caballero, la enmienda de Belton, con un carácter más partidista, pedía el reconocimiento formal del gobierno de Franco.

El profesor O’Sullivan defendió su enmienda presentando la guerra española como una batalla entre Comunismo y "Religionismo", y criticando al presidente por su interés por un pronto final de la guerra, sin importarle qué clase de final. Finalizó criticando al Comité de No Intervención por su falta de poder político en la práctica (17).

Por su parte, el diputado Belton basó la defensa de su enmienda en una cita de la carta pastoral del cardenal Primado de España, mediante la cual se reiteró en su visión de la guerra española como una lucha entre Cristo y el Anti-Cristo, para concluir que la decisión

(14) The Public Acts of the Oieracbtas, 1937. Ley $n^{2} 1$. pp. 3-11.

(15) D.D. LXV, 18/2/37, 598-599.

(16) D.D. LXV, 18/2/37, 598.

(17) D.D. LXV, 18/2/37, 608-619. 
que el Dáil afrontaba era si Irlanda iba a estar frente al gobierno del cristianismo o junto al gobierno del Anti-Cristo en España (18).

El debate abierto por la discusión de las enmiendas dio pie a debatir el significado global de la política irlandesa para con la guerra civil española. Así, a las críticas de O’Sullivan y de Belton siguieron otras críticas a la política gubernamental.

Por una parte, se censuró al gobierno por no alcanzar a comprender el sentido último de la guerra española. También se criticó la política de No Intervención, no sólo por los errores técnicos que dificultaban su aplicación, sino también por ir contra los deseos del pueblo irlandés, especialmente los de aquellos que voluntariamente querían "to go out and fight for a Catholic people in their fight against atheism" (19).

Por otra parte, la oposición también condenó al gobierno porque, con su política, estaba echando a perder la ascendencia moral que Irlanda disfrutaba entre los países cristianos de la Commonwealth. Se creyó que Irlanda les estaba fallando al no darles el liderazgo que esperaban y que, al hacer esto, se estaba alienando su apoyo en el caso de una crisis dentro del Imperio (20).

Una posición intermedia fue la mantenida por el diputado MacDermot, quien, aunque apoyaba la política del gobierno, no dejó de manifestar su esperanza en una victoria franquista. Para él, esta victoria vendría dada por la aplicación práctica de la ley, ya que una vez que ésta entrara en vigor, no permitiría que nuevos factores influyeran en la situación española, y siendo ésta favorable para Franco, no dudaba que la victoria se decantaría de su lado (21).

Finalmente, intervinieron los bancos del gobierno. En relación con el asunto de las relaciones diplomáticas, éstos las definieron más como relaciones entre países que como entre gobiernos (22), y explicaron que éstas habían de continuar aun cuando hubiera cambios de gobierno, o incluso de régimen, aclarando que la existencia de relaciones diplomáticas no implicaba ningún encomio o aprobación por parte de un gobierno de la política de otro (23). Esta explicación oficial de por qué el gobierno no estaba dispuesto a actuar en la direc-

(18) D.D. LXV, 18/2/37, 626-634.

(19) D.D. LXV , 18-24/2/37, 597-1.024.

(20) D.D. LXV, 19/2/37, 670 (Belton) y 691 (Dillon).

(21) D.D. LXV , 19/2/37, 678-684.

(22) D.D. LXV, 19/2/37, 760-761 (Derry).

(23) D.D. LXV, 19/2/37, 841-844 (De Valera). 
ción que la oposición estaba sugiriendo, se reforzó haciendo notar el hecho de que, hasta entonces, sólo los países fascistas habían reconocido al gobierno de Franco (24).

Una vez clarificada la posición sobre las enmiendas, el gobierno defendió la conveniencia de la política de No Intervención. De este modo, el diputado Derry consideró esa política como la más adecuada, tanto para llevar la guerra a su fin como para permitir al pueblo español elegir por sí mismo un gobierno de acuerdo a sus propias ideas (25); este derecho de los españoles también fue reconocido por el presidente (26). Finalmente, se señaló que la No Intervención también contaba con la ventaja de prevenir el inicio de una nueva guerra mundial (27).

Los resultados del largo debate fueron la derrota de las enmiendas por 56 votos a 39 (28) y la aprobación de la ley por 77 votos a 50 (29).

\section{B) Actividad legislativa posterior}

La Merchant Shipping (Spanish Civil War) Act (30), debatida y votada entre el 10 y el 11 de marzo de 1937 , puede ser considerada como un epílogo de la Spanish Civil War (Non-Intervention) Act.

Con la intención de cumplir la disposición del Acuerdo de No Intervención, que prohibía la exportación de material de guerra a España, se presentó ante el Comité un esquema para un plan de control que dispondría observadores en las fronteras españolas y en determinados puertos nacionalistas y republicanos (31). El plan quedó finalmente formulado para principios de 1937, e incluyó la adopción

(24) D.D. LXV, 24/2/37, 912 (MacDermot).

(25) D.D. LXV, 19/2/37, 757.

(26) D.D. LXV 19/2/37, 833 y 855 .

(27) D.D. LXV, 24/2/37, 1.021-1.022 (Macentee). El Irish Labour Party aprobó esta decisión, pero sólo pudo hacerlo saber varios días después, véase D.D. LXV, $11 / 3 / 37,1.731-1.732$.

(28) D.D. LXV, 19/2/37, 865-868. Votaron a favor los diputados del Fianna Fáil y algunos independientes, mientras que lo hicieron en contra los diputados del Fine Gael, más algunos otros independientes.

(29) D.D. LXV, 24/2/37, 1.021-1.024. Con los votos favorables de los diputados del Fianna Fáil, de los laboristas y de algunos independientes. Votaron en contra los del Fine Gael y un independiente.

(30) The Public Acts of the Oierachtas, 1937. Ley no 9. pp. 93-97.

(31) SCHWARTZ, FERNANDO. La internacionalización de la Guerra Civil Española. Barcelona, 1971. pp. 189-192 y 198-200. El plan fue presentado en noviembre de 1936, pero no contó con la aprobación final del gobierno nacionalista. 
de un sistema de observación en el lado no español de las fronteras y en los buques de pabellón perteneciente a los países firmantes del Acuerdo que navegaran hacia España; estableció un control marítimo por unidades navales de diferentes países y, por último, pretendió cubrir también la prohibición de las salidas de voluntarios con destino a España. Aunque aprobado por el Comité el 8 de marzo, no entró en vigor hasta abril, tras establecerse un International Board for NonIntervention, cuyos agentes habrían de informar sobre las posibles rupturas del Acuerdo (32).

Dado que la observación y el control de las fronteras requería la imposición de ciertas obligaciones sobre los barcos mercantes, y dado que la ley irlandesa no contaba en su curso ordinario con ninguna disposición que las contemplara, era necesaria una ley que estipulara que cualquier barco que se dirigiera hacia el territorio español pudiera ser llamado en cualquier lugar en ruta con el fin de ser abordado por cualquiera de los observadores internacionales. La Merchant Shipping (Spanish Civil War) Act daría a los miembros del International Board los poderes necesarios para interrogar a los pasajeros y a los tripulantes de los mercantes, así como para examinar sus cargas y documentos, contemplando también el derecho a controlar los barcos del Saorstát (33).

Durante el debate de la ley, los diputados O’ Higgins y MacGilligan hicieron algunas preguntas al ministro de Industria y Comercio solicitando información sobre el alcance en que, en término de barcos, la ley afectaría a Irlanda; sobre el coste estimado del plan y de la contribución de Irlanda; y sobre si los envíos de la Cruz Roja serían detenidos o considerados como material de guerra por los inspectores (34).

El ministro, Sr. Lemass, 'contestó que aunque había pocos barcos registrados en el Saorstát que fueran capaces de hacer viajes a España, era necesario asegurarse de que ellos no actuarían contrariamente a lo dispuesto por el plan de control. Sobre el gasto del plan, señaló que la contribución de Irlanda sería del $0,8 \%$, lo que podría significar un máximo de 8,000 libras, para cuya financiación el Dáil debería aprobar un presupuesto suplementario. Finalmente, declaró que nada que tuviera que ver con los suministros de la Cruz Roja sería considerado como material de guerra (35).

(32) Ibídem. pp. 238-244.

(33) D.D. LXV, 11/3/37, 1.720-1.721 (ministro de Industria y Comercio).

(34) D.D. LXV, 11/3/37, 1.722-1.725.

(35) D.D. LXV $11 / 3 / 37,1.726-1.728$. La suma extraordinaria fue aprobada el 9 de abril de 1937 después de otro debate sobre la eficiencia de la política de No Intervènción, véase D.D. L.XVI, 9/4/37, 643-694. 
La contribución irlandesa al programa no sería sólo financiera, sino que en total once irlandeses sirvieron bajo el Pacto de No Intervención, cuatro bajo el plan de observación terrestre y siete bajo el plan de observación marítima (36).

Finalmente, el 15 de febrero de 1939, otra suma extraordinaria fue votada en el Dáil, esta vez para sufragar, entre otros asuntos, los gastos de la retirada de los voluntarios de nacionalidad irlandesa de España (37) y para contribuir a los gastos de la International Commission for the Assistance of Child Refugees in Spain (38).

\section{EL PROBLEMA DE LAS RELACIONES DIPLOMATICAS ENTRE ESPAÑA E IRLANDA}

Aparte de la presión ejercida sobre el gobierno por el Irish Christian Front (39) y por la Iglesia Católica, los diputados del Fine Gael, así como también algunos diputados independientes, sin atacar explícitamente la política no-intervencionista, pidieron al gobierno la ruptura de las relaciones diplomáticas con el gobierno republicano y el reconocimiento del gobierno nacionalista.

El 27 de noviembre de 1936, Mr Cosgrave, el líder del Fine Gael en el Dáil Éireann, solicitó al parlamento "to express the view that the Government should take the necessary steps leading to the recognition by us of the government of General Franco in Spain" (40), justificando que se tomara tal decisión debido a que la lucha que se estaba desarrollando en España era una "for the victory of defeat of Communism and all it stands for it, with its denial of Christian principles, individual liberty and democracy", y no comprendiendo "how a country with our history, our beliefs, our traditions and our ideals, moral, religious and political, can fail to withdraw recognition from a Government standing for everything we abhor and accord it to a Government that is fighting enemies that are the greatest we have combat in Euro-

(36) D.D. LXX, 9/3/38, 627 (O Ceailaig). Para mayor información sobre el despliegue del control naval y terrestre véase SALAS LARRAZABAL, JESUS. Intervención extranjera en la Guerra de España. Madrid, 1974. pp. 357-362.

(37) D.D. LXXIV, 15/2/39, 481. Sub-título A (7).

(38) D.D. LXXIV, 15/2/39, 482. Sub-título A (9).

(39) Movimiento no partidista ideado y liderado por Patrick Belton -miembro independiente del Dáil- con el doble objetivo de combatir el comunismo en casa y enviar ayuda a las fuerzas patrióticas de España. Irisb Independent. 5 de octubre de 1937 (I. I. 5/10/37).

(40) D.D. LXTV, 27/11/36, 1.194. 
pe now or in the future". Para finalizar su intervención, declaró que su partido no estaba sugiriendo que se abandonara la política de No Intervención, política que ellos aprobaban por completo (41).

Inmediatamente después, el profesor O’Sullivan secundó la propuesta de Cosgrave, ya que, para él, la única alternativa en España era "victory for the Reds or for Franco", y en tales circunstancias la única postura posible pasaba por el reconocimiento del gobierno de Franco (42).

Entonces el Sr. MacDermot, más tarde llamado "fall guy" del gobierno (43), señaló que, aunque entre el gobierno de Franco y el gobierno de Largo Caballero apenas había nadie en la Cámara, y muy pocos en el país, que no prefirieran el de Franco, era necesario defender la política del gobierno dado lo difícil que resultaba encontrar el momento apropiado de reconocer un gobierno revolucionario, dándose el caso además de que, hasta entonces, sólo los gobiernos de corte fascista habían reconocido al gobierno de Franco. Lo mejor para Irlanda era, según MacDermot, actuar en concierto con el cuerpo general de países que no eran ni comunistas ni fascistas. Finalizó su intervención afirmando su creencia de que el gobierno estaba enteramente dispuesto, e incluso impaciente, por reconocer la administración del general Franco cuando llegara el momento oportuno (44).

Por último, el presidente concluyó el debate con un discurso, que empezó con unas precisiones sobre lo acertado del punto de vista de MacDermot y sobre el gradual debilitamiento del comunismo observado por su partido desde su llegada al poder, siendo el peligro comunista fruto de una campaña orquestada para confundir al pueblo irlandés. Una vez dicho esto, De Valera se centró en el tema del reconocimiento, y explicó que su gobierno seguiría la práctica usual de reconocer a un gobierno cuando éste presentara indicaciones claras de estabilidad, sin tener en cuenta la cuestión de las simpatías. El presidente finalizó expresando su satisfacción por contar con el beneplácito de la oposición en el tema de la idoneidad de la política de No Intervención, y explicó que ésta no era sólo la que podía evitar una conflagración general europea, sino que también permitiría que la guerra terminara tan rápido como fuera posible, y en unas condiciones que permitiera a la mayoría de los españoles vivir y progresar en la dirección que ellos desearan (45).

(41) D.D. LXIV, 27/11/36, 1.197.

(42) D.D. LXIV, 27/11/36, 1.203.

(43) D.D. LXV, 19/2/37, 723 (MacGilligan).

(44) D.D. LXIV, $27 / 11 / 36,1.208-1.213$.

(45) D.D. LXIV, 27/11/36, 1.217-1.224. 
En febrero de 1937 la cuestión del reconocimiento fue debatida de nuevo cuando el diputado MacDermot preguntó al ministro de Asuntos Exteriores si por ley y costumbre internacional el momento apropiado para reconocer a un nuevo gobierno, que se había establecido en el curso de una guerra civil o una revolución, era cuando se juzgaba que había conseguido estabilidad y asegurado obediencia sobre una clara mayoría del país y del pueblo y, en segundo lugar, si cuando el gobierno del general Franco cumpliera estas condiciones, el ministro consultaría a los otros países de la Commonwealth con el propósito de obtener un reconocimiento simultáneo (46).

El presidente contestó que no habría inconveniente en reconocer al gobierno de Franco cuando dichas condiciones se cumplieran. Sobre la segunda parte de la pregunta, De Valera señaló que, si se hiciera tal tipo de sugerencia, probablemente se haría con referencia a un grupo europeo, ya que eran los estados europeos los más directamente interesados en tomar la iniciativa que asegurara la estabilidad (47).

Durante la primera mitad de 1937 aún se siguió insistiendo sobre el mismo tema. Todavía en febrero, el diputado Dillon preguntó si era deseable y conveniente mantener relaciones diplomáticas con un gobierno que era notoriamente comunista (48). El mismo día, de nuevo se discutió el tema debido a las enmiendas presentadas al Spanish Civil War (Non-Intervention) Bill (49). En marzo fue sacado a discusión durante el debate del Central Fund Bill (50). En abril lo hicieron los diputados MacDermot, que preguntó sobre las actividades del ministro irlandés en España y sobre la existencia o no de relaciones comerciales entre Irlanda y España (51), y Doyle, que planteó el problema de los menores irlandeses envueltos en la guerra española (52). Aún antes de las elecciones generales, se pidió por dos veces que se suprimiera la oficina del ministro del Irish Free State en España (53).

Sin embargo, cuando en junio empezó la campaña para las elecciones generales, el asunto español fue suprimido de la mayoría de los discursos políticos irlandeses, para sólo encontrar un hueco en los

(46) D.D. LXV, 17/2/37, 332.

(47) D.D. LXV, 17/2/37, 332-333.

(48) D.D. LXV, 18/2/37, 485-486.

(49) Véase supra.

(50) D.D. LXV, 10/3/37, 1.440-1.441 (O’Higgings), 1.509 (MacGilligan) Y 1.553-1.560 (Belton).

(51) D.D. LXVI, 8/4/37, 469 y 474

(52) D.D. LXVI, 14/4/37, 717 .

(53) D.D. LXVI, 22/4/37, 1.483 (MacDermot) y LXVII, 19/5/37, 757 (Costello). 
mítines de Mr Belton (54) quien, casualmente, perdió su escaño (55). Por el contrario, las verdaderas preocupaciones de los políticos durante la campaña electoral fueron los pagos de las rentas vitalicias, la "guerra económica", la unidad de Irlanda y la nueva Constitución (56).

Desde ese momento, el reconocimiento del gobierno de Franco fue sólo ocasionalmente pedido (57), hasta que finalmente, el 15 de febrero de 1939, el presidente anunció que el gobierno irlandés había reconocido al gobierno de Franco como el gobierno de España. De Valera explicó que se había tomado tal decisión ya que "once Franco had reached a position of supreme authority or a position which was potentially that, the question of non-intervention was no longer at issue and the 'de facto' Government in Spain acquired a natural right to be recognized in law as the Government of that country" (58).

Para la derecha irlandesa la adopción de esta medida resultó ser un tanto tardía y no cumplió con sus esperanzas de ver a Irlanda tomando un liderazgo en este sentido. En efecto, la medida llegaba justamente después de que Bélgica, un país cuya postura había sido frecuentemente presentada como la propia de un país católico por la derecha irlandesa, hubiera decidido romper relaciones con el gobierno de Valencia y enviar un representante al gobierno nacionalista de Burgos (59). Por aquel tiempo también Francia había decidido establecer contactos con el gobierno de Franco y llegar a los acuerdos necesarios para nombrar un embajador francés en Burgos (60).

El intercambio oficial de embajadores puso punto final al tema del reconocimiento. El 10 de abril de 1939, Mr. L. H. Kerney, ministro irlandés en España, presentó sus credenciales al general Franco (61); por su parte, don Juan García Ontiveros fue nombrado ministro español en Irlanda (62).

(54) I.I. 26 y $29 / 6 / 37$.

(55) $1.1 .7 / 7 / 37$.

(56) Campaña electoral, I.I. 15/6/37 y días siguientes.

(57) D.D. LXIX, 14/12/37, 225 (O’ SULLIVAN) y LXXI, 24/5/38, 1.535 (Doyle).

(58) D.D. LXXIV, 15/2/39, 484-485.

(59) I.I. $29-30 / 11 / 38,2 / 12 / 38$ y $12-14 / 1 / 39$.

(60) I.I. 3/2/39. Véase también PIKE, DAVID W. Les Français et la Guerre d'Espagne. París, 1975. pp. 349-358.

(61) I.I. $11 / 4 / 39$,

(62) I.I. $13 / 4 / 39$ y $2 / 5 / 39$. 